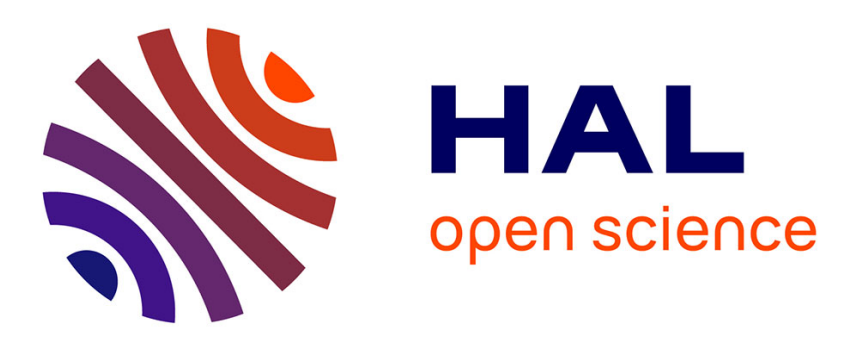

\title{
Estimates of genetic parameters for growth and wood properties in Eucalyptus pellita F. Muell. to support tree breeding in Vietnam
}

Tran D. Hung, Jeremy T. Brawner, Roger Meder, David J. Lee, Simon

Southerton, Ha H. Thinh, Mark J. Dieters

\section{To cite this version:}

Tran D. Hung, Jeremy T. Brawner, Roger Meder, David J. Lee, Simon Southerton, et al.. Estimates of genetic parameters for growth and wood properties in Eucalyptus pellita F. Muell. to support tree breeding in Vietnam. Annals of Forest Science, 2015, 72 (2), pp.205-217. 10.1007/s13595-014-0426-9 . hal-01284171

\section{HAL Id: hal-01284171 \\ https://hal.science/hal-01284171}

Submitted on 7 Mar 2016

HAL is a multi-disciplinary open access archive for the deposit and dissemination of scientific research documents, whether they are published or not. The documents may come from teaching and research institutions in France or abroad, or from public or private research centers.
L'archive ouverte pluridisciplinaire HAL, est destinée au dépôt et à la diffusion de documents scientifiques de niveau recherche, publiés ou non, émanant des établissements d'enseignement et de recherche français ou étrangers, des laboratoires publics ou privés. 


\title{
Estimates of genetic parameters for growth and wood properties in Eucalyptus pellita F. Muell. to support tree breeding in Vietnam
}

\author{
Tran D. Hung • Jeremy T. Brawner • Roger Meder • \\ David J. Lee • Simon Southerton • Ha H. Thinh • Mark J. Dieters
}

Received: 23 May 2014 / Accepted: 25 September 2014 / Published online: 24 October 2014

(C) INRA and Springer-Verlag France 2014

\begin{abstract}
- Key message Eucalyptus pellita demonstrated good growth and wood quality traits in this study, with young plantation grown timber being suitable for both solid and pulp wood products. All traits examined were under moderate levels of genetic control with little genotype by environment interaction when grown on two contrasting sites in Vietnam.

- Context Eucalyptus pellita currently has a significant role in reforestation in the tropics. Research to support expanded of use of this species is needed: particularly, research to better
\end{abstract}

Handling Editor: Jean-Michel Leban

Contributions by co-authors Tran Duy Hung: conception and design of project (50\%), statistical analysis (80 \%), wrote the paper $(60 \%)$.

Jeremy Brawner, Mark Dieters: conception and design of project (50\%), statistical analysis (20\%), wrote and edited paper (20\%).

Roger Meder, David Lee, Simon Southerton, Ha Huy Thinh: wrote and edited paper $(20 \%)$.

\author{
T. D. Hung $(\bowtie) \cdot M$. J. Dieters \\ The University of Queensland, School of Agriculture and Food \\ Sciences, St Lucia, QLD 4072, Australia \\ e-mail: d.tran3@uq.edu.au \\ T. D. Hung \\ e-mail: tranhungfrc@gmail.com
}

\author{
M. J. Dieters \\ e-mail: m.dieters@uq.edu.au \\ J. T. Brawner $\cdot$ R. Meder \\ CSIRO - Plant Industry, 306 Carmody Road, St. Lucia, QLD 4067, \\ Australia
}

\section{J. T. Brawner}

e-mail: Jeremy.Brawner@csiro.au

R. Meder

e-mail: Roger.Meder@csiro.au understand the genetic control of key traits will facilitate the development of genetically improved planting stock.

- Aims This study aimed to provide estimates of the heritability of diameter at breast height over bark, wood basic density, Kraft pulp yield, modulus of elasticity and microfibril angle, and the genetic correlations among these traits, and understand the importance of genotype by environment interactions in Vietnam.

- Methods Data for diameter and wood properties were collected from two 10-year-old, open-pollinated progeny trials of

\section{J. Lee}

Forest Industries Research Centre, University of the Sunshine Coast, Locked Bag 4, Maroochydore DC, QLD 4558, Australia e-mail: dlee@usc.edu.au

\section{J. Lee}

e-mail: David.Lee@daff.qld.gov.au

\section{J. Lee}

Department of Agriculture, Fisheries and Forestry, PO Box 395, Gympie, QLD 4570, Australia

S. Southerton

CSIRO - Plant Industry, CPO Box 1600, Canberra, ACT 2601, Australia

e-mail: Simon.Southerton@csiro.au

H. H. Thinh

Institute of Forest Tree Improvement and Biotechnology, Dong

Ngac, Tu Liem, Hanoi, Vietnam

e-mail: Ha.huy.thinh@vafs.gov.vn 
E. pellita in Vietnam that evaluated 104 families from six native range and three orchard sources. Wood properties were estimated from wood samples using near-infrared (NIR) spectroscopy. Data were analysed using mixed linear models to estimate genetic parameters (heritability, proportion of variance between seed sources and genetic correlations).

- Results Variation among the nine sources was small compared to additive variance. Narrow-sense heritability and genetic correlation estimates indicated that simultaneous improvements in most traits could be achieved from selection among and within families as the genetic correlations among traits were either favourable or close to zero. Type B genetic correlations approached one for all traits suggesting that genotype by environment interactions were of little importance. These results support a breeding strategy utilizing a single breeding population advanced by selecting the best individuals across all seed sources.

- Conclusion Both growth and wood properties have been evaluated. Multi-trait selection for growth and wood property traits will lead to more productive populations of E. pellita both with improved productivity and improved timber and pulp properties.

Keywords Eucalyptus pellita · Wood properties · Heritability $\cdot$ Genetic correlation

\section{Introduction}

Eucalyptus pellita F. Muell, or red mahogany, is a medium to large tree that can grow up to $40 \mathrm{~m}$ in height and over $1 \mathrm{~m}$ in diameter (Harwood 1998; Dombro 2010). Timber of this species from natural stands is easily sawn and suitable for poles, flooring, panelling and general construction (Hillis and Brown 1978; Harwood 1998). There are two disjunct areas of natural forest where E. pellita occurs: southern New Guinea (across both Papua New Guinea and Irian Jaya, lowlands with elevation below $100 \mathrm{~m}$ above sea level (asl)) and northern Queensland, Australia (elevation up to $600 \mathrm{~m}$ asl). E. pellita has good growth and high survival when grown in plantations located both within its natural distribution and as an exotic in the regions with mean annual rainfall from 1,080 to $3,550 \mathrm{~mm}$ and mean annual temperature from 19 to $27^{\circ}$ C (Clarke et al. 2009). The species currently plays an important role in reforestation in countries such as Brazil, Cuba, Indonesia, Malaysia and the Philippines and has been identified as suitable for plantation establishment on coastal sites of northern Queensland (Clarke et al. 2009).

Eucalyptus species are grown widely for pulp production in many countries (Eldridge et al. 1993; Poke and Raymond 2006) and are an important source of short fibre cellulosic pulp, which is used for high-quality writing and printing paper or tissue products (Raymond 2002; Raymond and Schimleck 2002; Schimleck et al. 2006). As with many other eucalypts, E. pellita is used for a variety of products. Sawn timber of red mahogany is used to make fine furniture and in construction, as well as for many other purposes (Clarke et al. 2009). In addition, E. pellita is also one of the preferred raw materials for the pulp and paper industry (Dombro 2010); its Kraft pulping and paper-making properties are acceptable, being very similar to those of plantation-grown Eucalyptus urophylla of the same age and slightly inferior to those of plantation-grown Eucalyptus globulus (Clarke et al. 2009).

Attributes that make this species attractive for plantation establishment are its fast growth, good stem straightness, good coppicing ability, broad adaptation to a range of environmental conditions, good resistance to pests and diseases and suitability for a variety of wood products (Clarke et al. 2009). Consequently, E. pellita is currently one of the main species used in afforestation in several countries (Harwood 1998; Leksono et al. 2008; Clarke et al. 2009; Brawner et al. 2010). In Vietnam, eucalypts are one of the most important groups of plantation species, supplying both solid wood and pulpwood for industrial applications. Several progeny trials and seed orchards of E. pellita have been established in Vietnam since 2002 (Kha et al. 2003). A better understanding of the genetic control of growth and wood properties in E. pellita is required to support genetic improvement efforts and its use in industrial plantations.

The present study used two progeny trials of E. pellita established in Vietnam to investigate the genetic control of growth and wood properties in 104 open-pollinated families derived from nine seed sources (three firstgeneration seed orchards in Australia and six provenance collections from the native stands). The objectives were to compare diameter at breast height (diameter), Kraft pulp yield, basic density, modulus of elasticity and microfibril angle among the seed sources; partition variation for all traits into genetic and environmental components and estimate the heritability of the traits; and estimate the genetic correlations among traits and trials. These parameters are important to estimate the direct and indirect responses from selection and to guide the development of an E. pellita breeding program in Vietnam.

\section{Materials and methods}

2.1 Study trials, genetic materials and assessment

This study evaluated two open-pollinated progeny trials of E. pellita at 10 years of age that were established in Vietnam in 2002 (Table 1). Trials were derived from open-pollinated seed 
Table 1 Location and design details of the E. pellita open-pollinated progeny trials established in Vietnam

\begin{tabular}{lll}
\hline Description & \multicolumn{2}{l}{ Trial } \\
\cline { 2 - 3 } & 1 & 2 \\
\hline Location & Pleiku-Gia Lai & Bau Bang-Binh Duong \\
Latitude & $13^{\circ} 58^{\prime} \mathrm{N}$ & $11^{\circ} 16^{\prime} \mathrm{N}$ \\
Longitude & $108^{\circ} 01^{\prime} \mathrm{E}$ & $106^{\circ} 37^{\prime} \mathrm{E}$ \\
Elevation (m asl) & 780 & 45 \\
Mean annual & 1,900 & 2,200 \\
precipitation (mm) & $9(94)$ & $9(98)$ \\
Genetic material & \\
Number of replicates & 6 & 8 \\
Number of trees per plot & 4 & 4 \\
Initial spacing $^{\mathrm{b}}$ & $4 \times 1.5 \mathrm{~m}$ & $4 \times 1.5 \mathrm{~m}$ \\
No. of trees at establishment $^{\mathrm{b}}$ & 2,496 & 4,200 \\
No. of trees after thinning $^{\mathrm{c}}$ & 657 & 470 \\
Planted date & Sep 2002 & Oct 2002 \\
\hline
\end{tabular}

${ }^{a}$ Genetic material included in trials with number of seed sources followed by the total number of families in parentheses

${ }^{b}$ Number of trees at establishment. Each four-tree row plot consists of a single open-pollinated family

${ }^{\mathrm{c}}$ Number of trees at the time of assessment in 2012 after the second thinning that retained the one best tree per plot

that had been collected from either selections within seedling seed orchards (SSOs) of range-wide collections (three seed orchards) or natural stands of $E$. pellita (six provenances). The three SSOs were developed in Australia, following a thinning protocol similar to that described below for the trials assessed for this study (refer to Harwood et al. (1997) for a full description). Based upon the results of Harwood et al. (1997), which showed that the Queensland populations were less productive than New Guinea populations, all selections from SSOs included in the Vietnam trials were derived from New Guinea families and all native range populations included were also of New Guinea origin (Table 2). There were 94 and 98 families in the Vietnamese trials established near Pleiku and Bau Bang, respectively, with a total of 104 families represented across the two trials. The number of families in common within each seed source ranged from 4 to 32 between the two trials with the composition of the two trials relatively balanced with respect to families within seed sources.

The two trial sites differed in growing conditions, with a strong contrast in elevation, temperature and rainfall (Table 1). Trial 1 (Pleiku) was established in the central highland plateau of Vietnam at an elevation of $780 \mathrm{~m}$ asl, in a cooler and lower rainfall environment. Trial 2 (Bau Bang) was located in southern Vietnam at a low elevation of $45 \mathrm{~m}$ asl. Both trials were established using row-column designs that were generated using the CycDesign (Williams et al. 2002). These trials were managed for conversion into SSOs by progressively removing inferior individual trees within family plots, in order to provide a source of improved seed for use in further plantation development. Both trials were thinned twice, with trial 1 thinned in 2007 and 2009 and trial 2 thinned in 2005 and 2007. After the first thinning of the four-tree row plots, the best two trees were retained in each plot, with the subsequent thinning leaving the single best tree in each plot.

Diameters were measured, and wood samples were collected from all remaining trees across the two trials in March 2012. Diameter over bark at breast height $(1.3 \mathrm{~m})$ was measured for all stems using a diameter tape. Wood swarf samples were taken at approximately $1.3 \mathrm{~m}$ above ground using a 16$\mathrm{mm}$ spade bit and a handheld electric drill. Samples were free of bark and collected to a depth of approximately $40 \mathrm{~mm}$ under bark. After sampling, the hole in each tree was sterilised with methylated spirits and sealed to minimise the risk of pathogen damage. The swarf samples were placed in labelled paper bags and air-dried. The dried samples were sifted to separate out wood fines $(<1 \mathrm{~mm})$, which were then transferred into glass vials $(45 \times 20 \mathrm{~mm}$ in size) for near-infrared (NIR) analysis. All samples were scanned to obtain NIR spectra on a Bruker MPA FT-NIR instrument (Bruker Optik, Ettlingen, Germany, www.bruker.com) with spectra between 4,000 and $15,000 \mathrm{~cm}^{-1}(\sim 700-2,500 \mathrm{~nm})$ obtained at $8 \mathrm{~cm}^{-1}$ resolution. Wood traits were estimated using data from the NIR spectra recorded for each sample in a manner similar to that described by Brawner et al. (2012). The spectral data were imported into The Unscrambler software (Camo Software, Oslo, Norway, www.camo.com, version 10.1) to predict the four wood traits using NIR calibration models (Appendix 1) developed previously by Meder et al. (2011). These are partial least square (PLS) regression models that were prepared using spectra transformed to their second derivatives following the Savitzky-Golay method (Savitzky and Golay 1964) with an integration window of 15 points and a second-order polynomial fit, to relate the NIR spectra to reference values previously determined using standard laboratory protocols for each wood property trait (Meder et al. 2011).

\subsection{Statistical analyses}

Statistical analyses were conducted using Genstat version 16.0 (www.vsni.co.uk). All across-trial analyses were indexed by trial, and data was standardised by trial and replicate within trial to have a zero mean and a phenotypic variance of one in order to eliminate scale effects (White et al. 2007). Mixed linear models were used to estimate genetic parameters using restricted maximum likelihood (REML, Patterson and Thompson 1971) and to generate best linear unbiased prediction (BLUPs, White and Hodge 1989) of the parental breeding values. $Z$ tests were conducted to determine if random effects were significantly different from zero, and Wald statistics were used to test the significance of fixed effects. All models 
Table 2 Genetic materials included in the two E. pellita progeny trials in Vietnam

\begin{tabular}{|c|c|c|c|c|c|c|c|c|}
\hline \multirow[t]{2}{*}{ Seed source } & \multirow[t]{2}{*}{ Location } & \multirow[t]{2}{*}{ State/province } & \multirow[t]{2}{*}{ Country } & \multicolumn{2}{|c|}{ Number of families within trials } & \multirow[t]{2}{*}{ Latitude $\left({ }^{\circ} \mathrm{N}\right)$} & \multirow[t]{2}{*}{ Longitude $\left({ }^{\circ} \mathrm{E}\right)$} & \multirow[t]{2}{*}{ Elevation $(\mathrm{m})$} \\
\hline & & & & 1 & 2 & & & \\
\hline 17854 & Bupul Muting & Irian Jaya & Indonesia & 10 & 12 & 7.21 & 140.36 & 40 \\
\hline 18197 & South of Kiriwo & WP & PNG & 4 & 4 & 8.25 & 141.30 & 45 \\
\hline 18199 & Serisa Village & WP & PNG & 31 & 32 & 8.36 & 141.26 & 45 \\
\hline 18955 & Serisa & WP & PNG & 7 & 7 & 8.33 & 141.26 & 45 \\
\hline 19206 & Kiriwo & WP & PNG & 4 & 6 & 8.25 & 141.30 & 45 \\
\hline 19207 & Goe & WP & PNG & 7 & 7 & 8.20 & 141.32 & 50 \\
\hline 19616 & Kairi SSO & QLD & Australia & 6 & 6 & 17.12 & 145.34 & 715 \\
\hline 19673 & Cardwell SSO & QLD & Australia & 11 & 11 & 18.24 & 146.06 & 20 \\
\hline 19718 & Melville SSO & NT & Australia & 14 & 13 & 11.34 & 130.34 & 20 \\
\hline
\end{tabular}

Seed source numbers are as allocated by CSIRO

WP Western Province, PNG Papua New Guinea, NT Northern Territory, QLD Queensland, SSO seed seedling orchard

assumed that the random effects were normally distributed with expectations of zero and corresponding variances. Estimates of genetic parameters were approximated using the observed components of variance estimated from the general linear model in similar manner to Brawner et al. (2011):

$\mathbf{y}_{i}=\mathbf{X} \mathbf{b}_{i}+\mathbf{Z} \mathbf{u}_{i}+\mathbf{e}_{i}$

where $\mathbf{y}_{\boldsymbol{i}}$ refers to phenotypic observations that are indexed by trait $i$ in bivariate models, $\mathbf{b}_{\boldsymbol{i}}$ is the vector of fixed effects, $\mathbf{u}_{\boldsymbol{i}}$ is the vector of random effects, $\mathbf{X}$ is the incidence matrix relating the $\mathbf{y}_{\boldsymbol{i}}$ observations to the $\mathbf{b}_{\boldsymbol{i}}$ fixed effects, $\mathbf{Z}$ is the incidence matrix relating the $\mathbf{y}_{\boldsymbol{i}}$ observations to the $\mathbf{u}_{\boldsymbol{i}}$ random effects, and $\mathbf{e}_{i}$ is the vector of random error terms.

\subsubsection{Single-trial analyses}

Single-trial analyses were first conducted separately to obtain estimates of variance components for each trait in each trial. The models included terms for random seed source and family (within seed source) effects in $\mathbf{u}_{i}$; where $\widehat{\sigma}^{2} s$ and $\widehat{\sigma}_{F}^{2}$ are the estimated variance components associated with these random effects, respectively. The family by replicate interaction effect was used to account for plots within trial, and the seed source by replicate interaction was pooled with the residual to eliminate singularities caused by trials containing different sets of families within the same seed source. The overall trial mean and replicates within trial were included as fixed effects in $\mathbf{b}_{\boldsymbol{i}}$. This model was used to generate estimates of the biased narrow-sense heritability and the proportion variance among seed source proportion (Table 3).

\subsubsection{Bivariate analyses between traits}

Bivariate analyses were then undertaken between the traits across the two trials. Variance components obtained from these analyses were used to estimate unbiased narrow-sense heritabilities and correlations referred to as type A genetic correlation (Table 5, White et al. 2007). For these bivariate analyses, variance and covariance estimates for all traits were taken from a linear mixed effects model as follows:

$\mathbf{y}_{i}=\mathbf{X}_{i} \mathbf{b}_{i}+\mathbf{Z}_{q i} \mathbf{q}_{i}+\mathbf{Z}_{u i} \mathbf{u}_{i}+\mathbf{Z}_{p i} \mathbf{p}_{i}+\mathbf{e}_{i}$

where $\mathbf{y}_{\boldsymbol{i}}$ is the vector of observations that is indexed $\boldsymbol{i}$ by each trait, $\mathbf{y}_{i}=\left[\begin{array}{l}\boldsymbol{y}_{\text {trait } 1} \\ \boldsymbol{y}_{\text {trait } 2}\end{array}\right] ; \mathbf{b}_{\boldsymbol{i}}$ is the vector of fixed effects representing the trial mean for each trait and replication; $\mathbf{X}_{i}$ is the incidence matrix relating the $\mathbf{y}_{\boldsymbol{i}}$ to the $\mathbf{b}_{\boldsymbol{i}}$ fixed effects, $\mathbf{X}_{i} \mathbf{b}_{i}=\left[\begin{array}{cc}\boldsymbol{X}_{1} & 0 \\ 0 & \boldsymbol{X}_{2}\end{array}\right]\left[\begin{array}{l}\boldsymbol{b}_{1} \\ \boldsymbol{b}_{2}\end{array}\right], \mathbf{0}$ is the null matrix; $\mathbf{q}_{\boldsymbol{i}}$ is the vector of random seed source effects $\sim \operatorname{MVN}\left(\mathbf{0}, \mathbf{L} \otimes \mathbf{I}_{i}\right)$, where $\mathbf{L}=\left[\begin{array}{cc}\hat{\sigma}_{S_{1}}^{2} & \hat{\sigma}_{S_{1,2}} \\ \hat{\sigma}_{S_{1,2}} & \hat{\sigma}_{S_{2}}^{2}\end{array}\right], \otimes$ is the Kronecker product and $\mathbf{I}_{\boldsymbol{i}}$ is an identity matrix of size equal to the number seed sources, $\widehat{\sigma}_{S_{i}}^{2}$ is the estimated seed source variance for trait $i$ and $\widehat{\sigma}_{S_{1,2}}$ is the covariance between seed sources for traits 1 and $2 ; \mathbf{u}_{i}$ is the vector of random open-pollinated family within seed source effects $\sim \operatorname{MVN}\left(\mathbf{0}, \mathbf{G} \otimes \mathbf{I}_{\boldsymbol{i}}\right)$, where $\mathbf{G}=\left[\begin{array}{cc}\hat{\sigma}_{F_{1}}^{2} & \hat{\sigma}_{F_{1,2}} \\ \hat{\sigma}_{F_{1,2}} & \hat{\sigma}_{F_{2}}^{2}\end{array}\right]$ with estimated variance between families $\left(\widehat{\sigma}_{F_{1}}^{2}\right)$ for the first and second traits, and between-trait family covariances $\left(\widehat{\sigma}_{F_{1,2}}\right) ; \mathbf{p}_{i}$ is the vector of random replicate by family within seed source interactions $\sim \operatorname{MVN}\left(\mathbf{0}, \mathbf{M} \otimes \mathbf{I}_{i}\right)$, where $\mathbf{M}=\left[\begin{array}{cc}\hat{\sigma}_{\operatorname{Repx} F_{1}}^{2} & \hat{\sigma}_{\operatorname{Repx} F_{1,2}} \\ \hat{\sigma}_{\operatorname{Repx} F_{1,2}} & \hat{\sigma}_{\operatorname{Repx} F_{2}}^{2}\end{array}\right], \widehat{\sigma}_{\operatorname{RepxFi}}^{2}$ is the estimated replicate variance for trait $i$, and $\widehat{\sigma}_{\operatorname{Repx} F_{1,2}}^{2}$ is the replicate covariance between traits 1 and 2 ; and $\mathbf{e}_{\boldsymbol{i}}$ is the vector of 
Table 3 Growth and wood traits from two progeny trials of Eucalyptus pellita established in Vietnam

\begin{tabular}{|c|c|c|c|c|c|c|}
\hline \multirow[t]{2}{*}{ Trait $^{\mathrm{a}}$} & \multirow[t]{2}{*}{ Trial } & \multirow[t]{2}{*}{ Mean } & \multicolumn{2}{|c|}{ Range $^{b}$} & \multirow{2}{*}{$\widehat{h}^{2}$} & \multirow{2}{*}{$\widehat{P}^{2}$} \\
\hline & & & Min & Max & & \\
\hline \multirow[t]{2}{*}{ Diameter $(\mathrm{cm})$} & Pleiku & $16.8(0.2)$ & 10.8 & 25.5 & $0.14(0.08)$ & $0.01(0.02)$ \\
\hline & Bau Bang & $21.0(0.3)$ & 9.3 & 34 & $0.33(0.11)$ & $0.04(0.04)$ \\
\hline \multirow[t]{2}{*}{ Density $\left(\mathrm{kg} / \mathrm{m}^{3}\right)$} & Pleiku & $657(3)$ & 554 & 829 & $0.23(0.13)$ & $0.04(0.04)$ \\
\hline & Bau Bang & $665(3)$ & 569 & 779 & $0.25(0.10)$ & $0.05(0.04)$ \\
\hline \multirow[t]{2}{*}{ Kraft pulp yield (\%) } & Pleiku & $46.8(0.1)$ & 42.6 & 51.7 & $0.29(0.14)$ & $0.03(0.02)$ \\
\hline & Bau Bang & $45.5(0.2)$ & 39.3 & 50.3 & $0.47(0.13)$ & $0.11(0.07)$ \\
\hline \multirow[t]{2}{*}{ Modulus of elasticity (GPa) } & Pleiku & $19.0(0.2)$ & 13.3 & 27 & $0.36(0.14)$ & $0.03(0.03)$ \\
\hline & Bau Bang & $19.5(0.2)$ & 13.6 & 29.5 & $0.51(0.14)$ & $0.10(0.07)$ \\
\hline \multirow[t]{2}{*}{ Microfibril angle $\left(^{\circ}\right)$} & Pleiku & $15.1(0.1)$ & 11 & 18.7 & $0.14(0.12)$ & $0.02(0.02)$ \\
\hline & Bau Bang & $14.5(0.2)$ & 9 & 19 & $0.48(0.13)$ & $0.10(0.06)$ \\
\hline
\end{tabular}

Overall mean, range of variation, estimates of biased narrow-sense heritability and seed source proportion of phenotypic variance from single-trial analyses (standard errors of means in parentheses)

${ }^{\text {a }}$ Diameter $=$ diameter at breast height over bark

${ }^{\mathrm{b}}$ Minimum and maximum values of individual traits observed in each trial

random residuals $\sim \mathrm{MVN}(\mathbf{R} \otimes \mathbf{I})$ where residuals were heterogeneous across traits, where $\mathbf{R}=\left[\begin{array}{cc}\widehat{\sigma}_{\text {Error }_{1}}^{2} & \widehat{\sigma}_{\text {Error }_{1,2}} \\ \widehat{\sigma}_{\text {Error }_{1,2}} & \widehat{\sigma}_{\text {Error }_{2}}^{2}\end{array}\right]$, $\widehat{\sigma}_{\text {Error }}^{2}$ is the estimated error variance for trait $i$, and $\widehat{\sigma}_{\text {Error }_{1,2}}^{2}$ is the estimated between-trait error covariance.

\subsubsection{Across-trial analyses}

Across-trial analyses for the same trait measured in two different trials were conducted to investigate environmental stability with type B correlations (Burdon 1977) and to estimate population-wide genetic parameters (Table 6). A similar linear mixed model (Eq. 2) as that described above for paired-trait analyses was used for the across-trial analyses of each trait, except the model was indexed by trial identification rather than assessment trait, where $\mathbf{y}_{\boldsymbol{i}}$ is the vector of observations indexed ( $i$ ) by trial: $\mathbf{y}_{i}=\left[\begin{array}{ll}\boldsymbol{y}_{\text {trial } 1} & \boldsymbol{y}_{\text {trial } 2}\end{array}\right] ; \mathbf{b}_{\boldsymbol{i}}$ and $\mathbf{X}_{\boldsymbol{i}}$ are defined as above; $\mathbf{q}_{\boldsymbol{i}}$ is the vector of random seed source effects $\sim \operatorname{MVN}\left(\mathbf{0}, \mathbf{L} \otimes \mathbf{I}_{\boldsymbol{i}}\right)$, where $\mathbf{L}=\left[\begin{array}{cc}\widehat{\sigma}_{S_{1}}^{2} & r_{S_{1,2}} \\ r_{S_{1,2}} & \widehat{\sigma}_{S_{2}}^{2}\end{array}\right]$ is a uniform correlation matrix, $r_{S_{x}}$ is a constant between-trial correlation, and $\widehat{\sigma}_{S_{N}}^{2}$ is estimated among-seed source variance in trials 1 to 2 for the trait; $\mathbf{u}_{\boldsymbol{i}}$ is the vector of random family within seed source effects $\sim \operatorname{MVN}\left(\mathbf{0}, \mathbf{G} \otimes \mathbf{I}_{i}\right)$, where $\mathrm{G}_{i}=\left[\begin{array}{cc}\widehat{\sigma}_{F_{1}}^{2} & \widehat{\sigma}_{F_{1,2}} \\ \widehat{\sigma}_{F_{1,2}} & \widehat{\sigma}_{F_{2}}^{2}\end{array}\right]$ is an unstructured variance/covariance matrix with $\widehat{\sigma}_{F_{N}}^{2}$ estimated for trait in each of the two trials, and $\widehat{\sigma}_{F_{N, N}}$ is the estimated genetic covariance estimated between each pair of trials; $\mathbf{n}_{\boldsymbol{i}}$ and $\mathbf{p}_{\boldsymbol{i}}$ is defined as above; $\mathbf{M}$ is a diagonal matrix of heterogeneous trial-specific plot variances; $\mathbf{e}_{\boldsymbol{i}}$ is defined as above; $\mathbf{R}$ is a diagonal matrix of the between-trial error variances.

Estimates of all model parameter were unconstrained, with the exception of the model used for the supplementary analysis of seed source interaction where all covariance components were constrained to keep parameters within the theoretical parameter space.

\subsubsection{Genetic parameter estimates}

Narrow-sense heritability estimates for single-trial and acrosstrial (biased and unbiased heritability estimates, respectively (Falconer and Mackay 1996)) analyses were estimated for all traits using the following formulae, which is the proportion of additive genetic variance to the within-seed source phenotypic variance:

$\widehat{h}^{2}=\frac{\widehat{V}_{A}}{\widehat{V}_{P}} \approx \frac{3 \widehat{\sigma}_{F}^{2}}{\widehat{\sigma}_{F}^{2}+\widehat{\sigma}_{\text {Error }}^{2}}$,

where $\widehat{V}_{A}$ is the estimated additive genetic variance, $\widehat{V}_{P}$ is the estimated phenotypic variance, $\widehat{\sigma}_{F}^{2}$ is the estimated betweenfamily variance (within seed source), and $\widehat{\sigma}^{2}$ Error is the estimated unexplained error (residual) variance. This heritability estimate assumes that the coefficient of relationship among families was one third due to the mixed mating that is expected in eucalypt species (Griffin and Cotterill 1988; Brawner et al. 2012), rather than one quarter as is appropriate for true half-sibs (Falconer and Mackay 1996). Between 
family variance components when estimated from a single site are biased upwards (Dieters et al. 1995), because the family and family $\times$ site variance components are confounded. Therefore, heritability estimated from a single site is referred to as 'biased narrow-sense heritability estimates'. The standard errors for heritability estimates were calculated using Dickerson's approximation following Dieters et al. (1995).

The proportion of seed source variance was used to estimate the relative importance of the among-provenance variance (Hodge and Dvorak 2001) and estimated as follows:

$\widehat{P}^{2}=\frac{\widehat{\sigma}^{2} s}{\widehat{V}_{p}}$

where $\widehat{\sigma}^{2} s$ is the estimated variance between seed sources, and $\widehat{V}_{p}$ is the estimated phenotypic variance as used to calculate heritability. Similarly estimates of $\widehat{P}^{2}$ from a single site are biased upwards due to confounding effects of any seed source by site variance.

Types A and B genetic correlations were calculated at the level of both family and seed source. Type A (family and seed source trait-trait) is a correlation between two different traits, whereas type B measures the genetic correlation between the same trait expressed on two different sites (Williams et al. 2002). These correlations can theoretically range between -1 and +1 , and estimates approaching \pm 1 indicate a very high degree of similarity of family performance for different traits or/and environments (Burdon 1977).

Types A and B correlations for family level were estimated as follows:

$r_{F}=\frac{\widehat{\sigma}_{F_{1,2}}}{\sqrt{\widehat{\sigma}_{F_{1}}^{2} \widehat{\sigma}_{F_{2}}^{2}}}$,

with the estimated genetic covariance $\widehat{\sigma}_{F_{1,2}}$ specific to a pair of traits for type A correlations or a pair of trials for type $\mathrm{B}$ correlations.

Types A and B correlations at the seed source level were estimated as follows:

$r_{\text {Prov }}=\frac{\widehat{\sigma}_{S_{1,2}}}{\widehat{\sigma}_{S_{1}}^{2} \widehat{\sigma}_{S_{2}}^{2}}$,

where $\widehat{\sigma}_{S_{1,2}}$ is the estimated covariance among seed sources for either pairs of traits or trials. The standard errors for genetic correlation estimates were calculated following the equation described by Falconer (1981).

\section{Results}

3.1 Results from single-trial analyses

\subsubsection{Variation among trials}

Summary statistics, biased narrow-sense heritability and seed source proportion of phenotypic variance estimates are given in Table 3. Mean values of most traits differed significantly between the two progeny trials. For growth, the mean value of diameter was significantly $(p<0.001)$ greater in the Bau Bang trial, $21.0 \mathrm{~cm}$ compared to $16.8 \mathrm{~cm}$ in the Pleiku trial. In terms of wood properties, density and modulus of elasticity had higher overall means in the Bau Bang trial; trial means for density were statistically different $(p<0.001)$, but trial means for modulus of elasticity did not differ significantly $(p=$ 0.098). Nonetheless, significantly $(p<0.01)$ greater Kraft pulp yield and microfibril angle were observed in the Pleiku trial, $46.8 \%$ and $15.1^{\circ}$ compared with $45.5 \%$ and $14.5^{\circ}$ in the Bau Bang trial. Estimates of both biased narrow-sense heritability and provenance proportion of phenotypic variance for most traits were much larger in the Bau Bang trial. The only exception was density, where estimates of single-trial genetic parameters were almost identical in the two trials. When comparing among traits, modulus of elasticity had the highest single-trial heritability estimates for the trait assessed at both trials, while diameter and microfibril angle were the lowest at the Pleiku trial, and density was lowest at the Bau Bang trial.

\subsubsection{Variation among seed sources}

The differences between seed sources were statistically significant $(p=0.013$ to $<0.001$ ) for all the traits evaluated.

Of the nine seed sources included in the two trials, two (19616 and 19718) grew consistently well in both trials. These originated from the SSOs in the highlands of Queensland and the monsoonal lowland environment of the Northern Territory, Australia, with 19616 ranked first and second, and 19718 ranked third in both the Pleiku and Bau Bang trials. DBH of these sources were significantly different from most other sources and from the trial means $(p=0.013$ and $p<0.001$ in the Pleiku and Bau Bang trials, respectively). There were two interactive seed sources, 18197 and 19673 (originating from south of Kiriwo, Papua New Guinea and Cardwell SSO in Queensland, Australia, respectively), which performed well in only one of the two trials. Source 18197 ranked second highest in the Pleiku trial but ranked lowest in the Bau Bang trial, while 19673 ranked first in the Bau Bang trial but ranked sixth in the Pleiku trial (Table 4). With the exception of 18197 , populations from the wild did not grow as well as the improved sources in either trial, demonstrating the combined effect of selection and increased out-crossing in these first generation trials. Interestingly, some evidence of local 
Table 4 Best linear unbiased predictions (standard deviations as given by Genstat version 16.0 in parentheses) for growth and wood quality traits for the seed sources evaluated in two Eucalyptus pellita open-pollinated progeny trials in Vietnam

\begin{tabular}{|c|c|c|c|c|c|c|c|c|c|c|c|c|}
\hline \multirow[t]{3}{*}{ Source } & \multirow{2}{*}{\multicolumn{2}{|c|}{$N$}} & \multicolumn{10}{|l|}{ Trait } \\
\hline & & & \multicolumn{2}{|c|}{ Diameter $(\mathrm{cm})$} & \multicolumn{2}{|c|}{ Density $\left(\mathrm{kg} / \mathrm{m}^{3}\right)$} & \multicolumn{2}{|c|}{ Kraft pulp yield (\%) } & \multicolumn{2}{|c|}{ Modulus of elasticity (GPa) } & \multicolumn{2}{|c|}{ Microfibril angle $\left({ }^{\circ}\right)$} \\
\hline & Pleiku & Bau Bang & Pleiku & Bau Bang & Pleiku & Bau Bang & Pleiku & Bau Bang & Pleiku & Bau Bang & Pleiku & Bau Bang \\
\hline 17854 & 48 & 77 & $16.8(2.4)$ & $20.7(2.9)$ & $666(35)$ & $675(32)$ & $46.8(1.5)$ & $45.5(1.8)$ & $19.2(1.8)$ & $19.2(1.6)$ & $15.1(1.2)$ & $14.8(1.3)$ \\
\hline 18197 & 17 & 24 & $17.5(2.9)$ & $20.0(3.4)$ & $664(35)$ & $660(29)$ & $47.0(1.4)$ & $46.3(1.2)$ & $19.8(1.7)$ & $19.7(1.6)$ & $14.7(1.2)$ & $14.2(1.1)$ \\
\hline 18199 & 131 & 202 & $16.6(2.2)$ & $20.1(3.5)$ & $648(38)$ & $659(33)$ & $46.7(1.6)$ & $45.5(1.7)$ & $18.4(2.2)$ & $18.8(1.9)$ & $15.4(1.2)$ & $14.9(1.3)$ \\
\hline 18955 & 31 & 40 & $16.1(2.0)$ & $20.1(4.4)$ & $640(33)$ & $655(36)$ & $46.8(1.4)$ & $45.6(2.1)$ & $18.3(2.3)$ & $18.4(2.1)$ & $15.4(1.3)$ & $15.2(1.4)$ \\
\hline 19206 & 19 & 39 & $16.2(2.0)$ & $20.0(4.0)$ & $655(33)$ & $668(32)$ & $46.5(1.2)$ & $46.0(1.3)$ & $18.6(1.7)$ & $19.7(1.4)$ & $15.4(1.3)$ & $14.2(0.8)$ \\
\hline 19207 & 33 & 40 & $16.4(2.3)$ & $20.9(3.4)$ & $651(27)$ & $670(33)$ & $46.2(1.5)$ & $45.7(1.8)$ & $18.7(1.7)$ & 19.5 (1.6) & $15.0(1.2)$ & $14.3(1.1)$ \\
\hline 19616 & 31 & 37 & $17.9(2.1)$ & $22.1(3.2)$ & $666(43)$ & $665(23)$ & $46.3(1.6)$ & $44.0(1.5)$ & $19.0(1.9)$ & $19.7(1.8)$ & $15.0(1.2)$ & $14.6(1.4)$ \\
\hline 19673 & 40 & 67 & $16.5(2.3)$ & $22.2(3.4)$ & 658 (39) & $651(36)$ & $47.5(1.4)$ & $45.1(1.9)$ & $19.3(2.1)$ & 20.9 (2.6) & 15.1 (1.6) & $13.6(1.7)$ \\
\hline 19718 & 120 & 131 & $17.2(2.4)$ & $21.9(3.1)$ & $667(43)$ & $676(36)$ & $47.0(1.5)$ & $46.0(1.7)$ & $19.6(2.3)$ & $19.8(2.0)$ & $14.8(1.2)$ & $14.2(1.3)$ \\
\hline Mean & 52 & 73 & $16.8(2.3)$ & $21.0(3.5)$ & 657 (39) & $665(34)$ & $46.8(1.5)$ & $45.5(1.8)$ & $18.9(2.1)$ & $19.5(2.1)$ & $15.1(1.2)$ & $14.5(1.4)$ \\
\hline
\end{tabular}

$N$ number of observations assessed from each seed source

adaptation was noted, as the highland seed orchard (19616) performed best in the highland trial (Pleiku) but changed rank across trials, while the lowland seed orchard (91673) performing best in the lowland trial. While this may reflect the genetic composition of the families included in these trials from the first-generation orchards, the lowland trial demonstrates a reversal of the SSO rankings with no significant differences between the two first-generation trials evident.

In terms of wood quality traits, sources 19718,19616 , 17854 and 18197 had the highest density and were significantly different from the Pleiku trial mean $(p<0.001)$, with 19718 and 17854 demonstrating superiority in the Bau Bang trial. The other sources had lower density and/or were not significantly different $(p>0.05)$ from the trial mean. For Kraft pulp yield, rankings were inconsistent for most sources across the two trials; however, 18197 and 19718 ranked well in both the Pleiku and Bau Bang trials. The inconsistency in rankings is demonstrated by 19673, which ranked first in the Pleiku trial and ranked eighth in the Bau Bang trial for Kraft pulp yield. Differentiation among seed lots reflects the seed source proportion of phenotypic variance $\left(\widehat{P}^{2}\right)$ estimates of Table 3 with a much smaller level of variation accounted for by seed sources evident in Pleiku (0.03) relative to Bau Bang (0.11). While only one source (19673) was found to have significantly $(p=0.005)$ greater Kraft pulp yield than the trial mean at the Pleiku trial, significant $(p<0.001)$ differences in Kraft pulp yield from the trial mean were found for three sources (18197, 19206 and 19718) at the Bau Bang trial. In contrast to Kraft pulp yield, three sources (18197, 19718 and 19673) had significantly higher modulus of elasticity than the trial mean in the Pleiku trial; however, there was only one source (19673) in the Bau Bang trial with modulus of elasticity significantly higher than the trial mean. For microfibril angle, the best source in the Bau Bang trial was 19673 with the lowest microfibril angle $\left(13.6^{\circ}\right)$. Three other sources $(18197,19206$ and 19718) also had significantly $(p<0.001)$ lower microfibril angle than the trial mean in this trial. In the Pleiku trial, two sources (18197 and 19718) had the lowest microfibril angle (14.7 and 14.8, respectively) and were significantly less than the trial mean $(p=0.009)$ (see Table 4$)$.

\subsection{Results from across-trial analyses}

\subsubsection{Genetic parameter estimates from trait-trait correlations}

The across-trial (unbiased) narrow-sense heritability, seed source proportion of phenotypic variance, family genetic correlation and seed source genetic correlation estimates estimated using Eq. 2 are presented in Table 5. For all traits, heritability estimates were far larger than the proportion of variance between seed sources; this indicates that additive variation was greater than the variance between seed sources. It should be noted that seed was sourced exclusively from New Guinea, and it is highly likely that the inclusion of populations from Queensland would have increase the proportion of variance between seed sources. Of these, the greatest heritability estimates were found for modulus of elasticity and microfibril angle $(0.39 \pm 0.09$ and $0.37 \pm 0.08$, respectively $)$ while the heritability of DBH was moderate $(0.32 \pm 0.08)$ and low for density $(0.20 \pm 0.07)$. In contrast to many other forest tree species, there was zero genetic correlation found for DBH 
Table 5 Genetic parameter estimates from bivariate across-trial analyses of growth and wood traits assessed in two Eucalyptus pellita progeny trials

\begin{tabular}{|c|c|c|c|c|c|}
\hline Trait & $\mathrm{DBH}$ & DEN & KPY & MOE & MfA \\
\hline \multicolumn{6}{|c|}{ Family level parameter estimates } \\
\hline $\mathrm{DBH}$ & $0.32(0.08)$ & & & & \\
\hline DEN & $0.00(0.00)$ & $0.20(0.07)$ & & & \\
\hline KPY & $-0.12(0.17)$ & $0.07(0.20)$ & $0.34(0.08)$ & & \\
\hline MOE & $0.26(0.16)$ & $0.78(0.08)$ & $0.52(0.12)$ & $0.39(0.09)$ & \\
\hline MfA & $-0.19(0.16)$ & $-0.65(0.11)$ & $-0.36(0.14)$ & $\mathrm{CF}$ & $0.37(0.08)$ \\
\hline \multicolumn{6}{|c|}{ Seed source level parameter estimates } \\
\hline DBH & $0.02(0.02)$ & & & & \\
\hline $\mathrm{DEN}$ & $0.76(0.21)$ & $0.04(0.02)$ & & & \\
\hline KPY & $-0.31(0.55)$ & $0.17(0.42)$ & $0.04(0.03)$ & & \\
\hline MOE & $0.93(0.08)$ & $0.29(0.35)$ & $0.05(0.46)$ & $0.07(0.04)$ & \\
\hline MfA & $-0.82(0.17)$ & $-0.26(0.33)$ & $-0.22(0.41)$ & $\mathrm{CF}$ & $0.06(0.03)$ \\
\hline
\end{tabular}

Family parameter estimates include narrow-sense heritability on the diagonal (bold) and type A additive genetic correlations below the diagonal. Seed source parameter estimates include proportion of phenotypic variance on the diagonal and type A seed source correlations below the diagonal (approximate standard errors of estimates are given in parentheses)

$D B H$ diameter at breast height over bark, $D E N$ wood basic density, $K P Y$ Kraft pulp yield, $M O E$ modulus of elasticity, $M f A$ microfibril angle, $C F$ convergence failed

and density at the family level and a high correlation at the seed source level was associated with a high standard error (Table 5). Similarly, a very high correlation between DBH and modulus of elasticity was found for seed sources, but the correlation was low at the family level. DBH was negatively correlated with both Kraft pulp yield and microfibril angle at both the family and seed source levels. Among wood quality traits, microfibril angle was moderately $(-0.36)$ and strongly $(-0.65)$ correlated at the family level with Kraft pulp yield and density, respectively. Unfortunately, the genetic relationship between microfibril angle and modulus of elasticity was not estimable for this species as the convergence of these REML analyses failed. A very low additive genetic correlation with high standard error was found between density and Kraft pulp yield with these two traits highly correlated with modulus of elasticity (Table 5).

\subsubsection{Genetic parameter estimates from trial-trial correlations}

Unbiased narrow-sense heritability and the seed source proportion of phenotypic variance estimates from across-trial analyses (Table 6) were similar to those estimated from single-trial analyses (Table 5) with single-trial heritability estimates typically higher than estimates from across-trial analyses. All type B seed source correlations were moderate to strong with the exception of Kraft pulp yield (Table 6). The same pattern was evident for type B additive genetic correlations indicating genotype by environment interactions not significant.

\section{Discussion}

4.1 Trial means and variation among seed sources

The representation of seed sources and families within seed source were similar in the two trials; therefore, trial differences expressed in mean values are assumed to be caused largely by differences in the environmental conditions (Pliura et al. 2007) experienced by the progeny trials. The slower growth rate observed in the Pleiku trial was likely due to cooler and drier climatic conditions as this trial is located on the high central plateau in Vietnam. Significantly higher $(p<0.001)$ growth found in the Bau Bang trial, most probably resulting from higher annual rainfall and warmer temperatures associated with lower elevation and latitude of this trial (Table 1). Significant site effects for growth traits (tree height and diameter) have been reported for E. pellita at four sites in Indonesia (Leksono et al. 2008). In comparison with a temperate eucalypt at a similar age (11 years of age), trial mean found for diameter at Bau Bang was similar with the overall mean of diameter of E. globulus reported by Apiolaza et al. (2005). Unexpectedly, higher wood density and modulus of elasticity, and lower microfibril angle were not observed in the less productive trial (Pleiku), as higher growth rates are expected to result in decreasing wood density and modulus of elasticity, and increasing microfibril angle (Zobel and van Buijtenen 1989). In contrast, significantly $(p<0.05)$ greater Kraft pulp yield was evident at the Pleiku trial. Density, modulus of elasticity and microfibril angle means found in the present study are somewhat higher than those previously reported in 
Table 6 Genetic parameter estimates from analyses for growth and wood traits in two Eucalyptus pellita progeny trials

\begin{tabular}{|c|c|c|c|c|c|c|c|c|c|c|}
\hline \multirow[t]{2}{*}{ Trial/trait } & \multicolumn{2}{|l|}{ Diameter } & \multicolumn{2}{|l|}{ Density } & \multicolumn{2}{|c|}{ Kraft pulp yield } & \multicolumn{2}{|c|}{ Modulus of elasticity } & \multicolumn{2}{|c|}{ Microfibril angle } \\
\hline & Pleiku & Bau Bang & Pleiku & Bau Bang & Pleiku & Bau Bang & Pleiku & Bau Bang & Pleiku & Bau Bang \\
\hline \multicolumn{11}{|c|}{ Family level parameter estimates } \\
\hline Pleiku & $0.30(0.13)$ & & $0.25(0.13)$ & & $0.28(0.13)$ & & $0.35(0.14)$ & & $0.14(0.12)$ & \\
\hline Bau Bang & $1.0(0.0)$ & $0.41(0.12)$ & $0.71(0.16)$ & $0.25(0.1)$ & $0.85(0.07)$ & $0.46(0.13)$ & $0.60(0.15)$ & $0.51(0.14)$ & $1.0(0.0)$ & $0.49(0.13)$ \\
\hline \multicolumn{11}{|c|}{ Seed source level parameter estimates } \\
\hline Pleiku & $\mathrm{CF}$ & & $0.04(0.03)$ & & $0.03(0.04)$ & & $0.04(0.03)$ & & $0.02(0.02)$ & \\
\hline Bau Bang & & & $0.97(0.04)$ & $0.05(0.03)$ & $0.10(0.61)$ & $0.11(0.08)$ & $0.78(0.21)$ & $0.11(0.07)$ & $0.60(0.23)$ & $0.16(0.04)$ \\
\hline
\end{tabular}

Narrow-sense heritability estimates or the proportion of variance between seed sources are given on the diagonals (bold). Type B (among trials) additive genetic and seed sources correlations are given below the diagonal. Approximate standard errors of each estimate are given in the parentheses

Notes: $\mathrm{CF}=$ convergence failed

ITTO (2006) for E. pellita at 13 years of age $\left(630 \mathrm{~kg} / \mathrm{m}^{3}\right.$, $17.3 \mathrm{GPa}$ and $10.2^{\circ}$, respectively). Likewise, E. pellita had greater wood density means (657 and $665 \mathrm{~kg} / \mathrm{m}^{3}$ in the Pleiku and Bau Bang trials, respectively) when compared with trial means of E. globulus, with ranges from 520 to $547 \mathrm{~kg} / \mathrm{m}^{3}$ (Miranda and Pereira 2002), $492 \mathrm{~kg} / \mathrm{m}^{3}$ (Apiolaza et al. 2005), and 482 to $488 \mathrm{~kg} / \mathrm{m}^{3}$ (Downes et al. 2006). Tran et al. (2010) also found lower wood density $\left(521 \mathrm{~kg} / \mathrm{m}^{3}\right)$ for E. urophylla in a progeny trial established in northern Vietnam. However, wood density observed in the present study was similar to that reported for E. pellita by Lee et al. (2011) and much lower than estimates $\left(750 \mathrm{~kg} / \mathrm{m}^{3}\right)$ reported by Brawner et al. (2012) for another eucalypt species, Corymbia citriodora. In contrast with wood density, mean values of Kraft pulp yield found here (45.5 and $46.8 \%$ ) were lower than those found for E. globulus: 56.9 to $60.9 \%$ (Miranda and Pereira 2002), $51.57 \%$ (Apiolaza et al. 2005) and $52.2 \%$ (Costa e Silva et al. 2009).

In this study, comparisons among the Kairi and Cardwell orchards are of interest as Kairi and Pleiku are at higher elevation and experienced lower mean annual temperatures and precipitation than Cardwell and Bau Bang. The Northern Territory SSO was established in a monsoonal environment at Yapilika on Mellville Island to the north of Darwin - a site with very distinct wet and dry seasons. The data allowed for an estimate of local adaptation brought about by selection for growth in contrasting first-generation trials, with families selected from a first-generation trial on the Tablelands of Queensland shown to be more productive (i.e. larger average diameter, $p<0.001$ for the contrast between 19616 and 19673 at Pleiku) than families selected from the first-generation trial in the Queensland lowlands when tested in the Vietnamese highlands. While the reverse was true in the lowland Vietnamese trial where the ranking of these seed lots reversed, differences were not significant.
Of the three seed sources that were collected from progeny trials that had been thinned into SSOs in Australia, two (19616 from the highland tropics of Atherton Tablelands and 19718 from the monsoonal tropics of Melville Island) grew well across both trials. The third seed source, which originated from a progeny trial established in a high rainfall, lowland Australian environment, did not perform well in the drier, highland Vietnamese trial. The better seed sources were represented by open-pollinated families from trees selected in thinned SSOs in Australia, with 19616 represented as open-pollinated families from six trees selected from within the Kairi progeny trial and 19718 represented by 13 or 14 families selected on Melville Island. The entire Kairi orchard was derived from Bupul-Muting (PNG) families, and the Melville trial was derived from seven provenances representing the range of the species in Australia and New Guinea. Both first- and second-generation families from New Guinea were used to establish the trials in Vietnam, and this allowed comparisons between New Guinea populations sourced from either the wild or planted forests managed as SSOs established in Australia. These comparisons demonstrate improvement that has been achieved through selection and/or increased out-crossing in managed orchards. The average diameters of families sourced from the three Australian orchards were 4 to $9 \%$ larger than the diameters of the families sourced from natural populations in New Guinea. This difference is still evident even after thinning of inferior trees. This may be interpreted as a genetic gain but may be inflated by competition effects (i.e. between row plots).

Several seed sources achieved high growth rates at only one site. For instance, 19673 (from the Cardwell SSO in the humid lowlands of Queensland) performed best (ranked first) in the Bau Bang trial but grew relatively poorly in the upland Pleiku trial. Unimproved material originating from the native forests of Papua New Guinea and Indonesia typically did not 
have high growth rates relative to families selected from the Australian SSOs. Nonetheless, at earlier ages in a trial established in Malaysia, the growth of two New Guinean provenances clearly outperformed the SSO seed sources, and Papua New Guinean provenances were superior to all Queensland provenances tested at a trial in the Northern Territory, Australia (Harwood et al. 1997). The growth of E. pellita found in the literature varies markedly. Kha et al. (2003) reported that at 8 years of age at central Vietnam diameter of six provenances ranged from 8.4 to $10.2 \mathrm{~cm}$. At the same time, Hardiyanto (2003) showed that E. pellita grew much faster in Indonesia, with diameter of 20.6 to $21.5 \mathrm{~cm}$ at 7.5 years of age. While studies on the growth rates for E. pellita are available in the published literature, little can be found for the wood properties of E. pellita. In this study, the source from Melville Island SSO (19718) was superior for wood quality traits across the two trials. This seed source not only grew well but also had relatively high density, Kraft pulp yield and modulus of elasticity, and low microfibril angle. Another seed source from the Kairi SSO in Queensland (19616) also grew well across the two trials; however, this seed source had lower Kraft pulp yield, but its density and modulus of elasticity were quite high.

\subsection{Genetic parameter estimates}

Estimates of biased narrow-sense heritability at younger ages (Luo et al. 2006) ranged from $0.19 \pm 0.03$ to $0.25 \pm 0.05$ for diameter seem to fit reasonably with those found in the present study. However, the current across-trial (or unbiased) heritability estimates found for diameter are somewhat greater than those previously reported, with a range of $0.30 \pm 0.13$ to $0.41 \pm 0.12$ compared with 0.22 to 0.25 at six years of age (Leksono et al. 2006), and 0.15 to 0.25 (Leksono et al. 2008) and 0.15 to 0.33 (Brawner et al. 2010) at younger ages ( 1 to 3 years of age). A reason for this may be the use of one third rather than one quarter for the coefficient of relationship (Hodge et al. 2002). Another factor may be due to the fact that these trials were thinned twice and thinning can inflate heritability estimates (Matheson and Raymond 1984). Across-trial heritability estimates for wood quality traits indicated that these traits are under moderate levels of genetic control. As the present study is the first to provide pair-site genetic parameter estimates for wood properties of E. pellita, comparisons are made with other Eucalyptus species.

The heritability estimate for wood density $(0.20 \pm 0.07)$ found here was low when compared to the range of values reported previously for other eucalypts. Sanhueza et al. (2002) reported heritability estimates for pilodyn penetration (an indirect measurement of wood density) of E. globulus at 4 and 5 years of age of 0.33 and 0.35 , respectively. Moderate heritability $(0.37)$ was also found for pilodyn penetration of E. globulus grown in a range of sites in Portugal, with ages ranging from 4 to 11 years (Costa e Silva et al. 2009). These differences may be caused by a number of reasons, such as different tree species assessed, the methods of estimation of wood density (pilodyn penetration versus NIR spectroscopy) and the ages of trees. However, heritability estimates for Kraft pulp yield, modulus of elasticity and microfibril angle in the present study are within the range of those previously published elsewhere for eucalypts (Raymond 2002; Schimleck et al. 2004; Apiolaza et al. 2005; Costa e Silva et al. 2009). Estimates of the proportion of variance among seed source were consistently lower than heritability estimates, suggesting that additive variance is more important than variation among PNG sources; however, as noted earlier, this may result from the deliberate exclusion of north Queensland sources.

Genetic correlations are useful to understand the importance of acclimation for the species in a range of sites and to make inferences about indirect responses on one trait from selection on others. Of these traits, growth, wood density and Kraft pulp yield are of particular importance as they can strongly impact pulp productivity (Borralho et al. 1993; Greaves et al. 1997). However, the present study found that there was no additive genetic correlation among diameter and wood density, which agrees with Miranda et al. (2001) who also found no correlation between growth and wood density in E. globulus. The additive genetic correlation between diameter and Kraft pulp yield found here was unfavourable (negative, see Table 5). Nevertheless, reports from previous studies upon the correlations among growth and wood density, and growth and Kraft pulp yield are often conflicting. For E. globulus, MacDonald et al. (1997) and Sanhuaeza et al (2002) reported slightly positive correlations among pilodyn and diameter, and for mean annual volume increment and pilodyn ( 0.25 and a range of 0.09 to 0.22 , respectively); however, other authors report weak (Hamilton et al. 2010) to moderate (Wei and Borralho 1997; Apiolaza et al. 2005) negative correlations between wood density and diameter. Further, on two sites investigated for Eucalyptus nitens, Hamilton et al. (2009) report the additive genetic correlations among wood density and diameter were moderate and negative for one site and positive for the other. Similarly, for E. globulus, although the genetic correlation between Kraft pulp yield and diameter was positive in Costa e Silva et al. (2009), it was negative in Apiolaza et al. (2005). These differences in the genetic correlations among growth and wood density, and growth and Kraft pulp yield may be due to the different ages of assessment at the same site (MacDonald et al. 1997; 
Hamilton et al. 2010) and different sites of assessment (Apiolaza et al. 2005; Costa e Silva et al. 2009). In the present study, the genetic correlation obtained for wood density and Kraft pulp yield were positive but not significantly different from zero. This correlation for wood density and Kraft pulp yield is consistent with Costa e Silva et al. (2009) who showed a genetic correlation between pilodyn and pulp yield was 0.05 . The strongly positive genetic correlation between modulus of elasticity and wood density observed here corresponds with other studies on E. nitens (Blackburn et al. 2010) and softwood species (Dungey et al. 2006). While we were unable to calculate a correlation between microfibril angle and modulus of elasticity due to convergence failure in REML analyses, genetic correlations between microfibril angle and all other traits were favourable in the current study, suggesting the genetic correlation between microfibril angle and modulus of elasticity is also likely to be favourable. This was consistent with previous estimates of correlations among microfibril angle and diameter, microfibril angle and wood density, and microfibril angle and Kraft pulp yield for other species (Apiolaza et al. 2005; Baltunis et al. 2007).

Different traits had different magnitudes of genotype by environment interaction found in this study for E. pellita. On one hand, type $\mathrm{B}$ genetic correlations among sites for diameter and microfibril angle were both 1.0, indicating that there was no genotype by environment interaction for these traits. This suggests that estimated breeding values for these two traits will rank similarly across sites. This corresponds with the findings of Brawner et al. (2010b) for diameter, where the correlation between sites in Indonesia was reported to be moderate to strong (0.49 to 0.79$)$. Type B genetic correlations for wood density and Kraft pulp yield among trials were above 0.70 , indicating low genotype by environment interaction. However, genetic correlation estimates for modulus of elasticity between the two trials were lower at 0.60 , suggesting genotype by environment interaction may be more important for this trait. On the other hand, at the seed source level (with the exception for diameter as the convergence failed in REML analysis), type B correlation for microfibril angle among trials was only moderately high (0.60). In addition, type B seed source correlation for Kraft pulp yield was very small and not significantly different from zero. This implies that for Kraft pulp yield, the performance of provenances was inconsistent across the two trials. Nonetheless, type B seed source correlations for wood density and modulus of elasticity were very high and positive ( 0.97 and 0.78 , respectively), indicating a low level of seed source by environment interaction observed in these trials. The results presented herein suggest that all assessed traits, at the family level, are likely to be moderately-high to highly stable across environments.

\section{Conclusion}

The results of this study indicate that the growth rates of E. pellita were good on contrasting sites in Vietnam and that its wood properties are suitable for both pulping and solid timber production. Genetic parameters were estimated for five industrially important traits in red mahogany from two openpollinated progeny trials. Heritability estimates were lower for diameter and wood density than for Kraft pulp yield, modulus of elasticity and microfibril angle. However, these traits are under moderate genetic control and therefore the species can offer good opportunities for substantial genetic improvement of these traits. The negative correlations between microfibril angle and other traits were favourable. However, the negative correlation between diameter and Kraft pulp yield, as well as the zero or low correlations between diameter and wood density, and between Kraft pulp yield and wood density were neutral. The largest correlation between wood traits was between wood density and modulus of elasticity at the family level. Variation was much higher at the family level than the seed source level, and genotype by environment interactions were low between these two trials.

These results indicate that selection of the best individuals (i.e. those with highest breeding values) across all seed sources of E. pellita is likely to lead to significant gains in key growth and wood property traits, as heritability of these traits were moderate to high and variation between the PNG seed sources evaluated was relatively small compared to variation between families for all traits except density. Given the observed trait-trait correlations, multi-trait selection in E. pellita can be expected to lead gains in both growth and wood property traits, improving the suitability of the species for production of both timber and pulpwood. The results are important to improve the understanding the genetic control of economically important traits and for directing ongoing E. pellita breeding and improvement programs in Vietnam and elsewhere.

Acknowledgments We would like to thank Mr Paul MacDonell and Mr Nguyen Van Chinh for their help with data and wood sample collection. Particular thanks to Dr. Katherine Raymont who provided instruction for scanning wood samples through an NIR instrument. We wish to thank the Institute of Forest Tree Improvement and Biotechnology (Vietnamese Academy of Forest Science), where the trials were undertaken, and collaborators for management and data collection.

Funding This study was financially supported by the University of Queensland, the Commonwealth Scientific and Industrial Research Organisation, Department of Agriculture, Fisheries and Forestry (Australia) and Ministry of Education and Training (Vietnam) 


\section{Appendix 1}

Table 7 The calibration statistics for the near infrared (NIR) calibration models used in the prediction of pulp yield, density, modulus of elasticity and microfibril angle

\begin{tabular}{lllllllllll}
\hline Trait & $\boldsymbol{R}_{\boldsymbol{C}}^{2}$ & RMSEC & RMSEV & No. of factors & Outliers excluded & No. of samples & $\boldsymbol{R}_{\boldsymbol{P}}^{2}$ & RMSEP & SEP & Reference \\
\hline Kraft pulp yield (\%) & 0.94 & 2.1 & 2.1 & 5 & 24 & 729 & 0.80 & 2.1 & 2.1 & (Meder et al. 2011) \\
Density $\left(\mathrm{kg} / \mathrm{m}^{3}\right)$ & 0.64 & 47 & 49 & 7 & 27 & 1,028 & 0.61 & 49 & 49 & Unpublished data \\
Modulus of elasticity (GPa) & 0.78 & 2.2 & 2.3 & 5 & 75 & 1,923 & 0.77 & 2.2 & 2.3 & Unpublished data \\
Microfibril angle $\left({ }^{\circ}\right)$ & 0.65 & 2.2 & 2.3 & 5 & 10 & 1,923 & 0.63 & 2.2 & 2.2 & Unpublished data \\
\hline
\end{tabular}

All models used second derivative in treatment procedure

$R_{C}^{2}$ coefficient of determination for the calibration model, RMSEC root mean square error of calibration, $R M S E V$ root mean square error of cross validation, No. of factors number of factors used in NIR model development, No. of samples number of samples used in model calibration, $R_{P}^{2}$ coefficient of determination for the prediction, RMSEP root mean square error of prediction, SEP standard error of predicted residuals

\section{References}

Apiolaza LA, Raymond CA, Yeo BJ (2005) Genetic variation of physical and chemical wood properties of Eucalyptus globulus. Silvae Genet 54:160-166

Baltunis BS, Wu HX, Powell MB (2007) Inheritance of density, microfibril angle, and modulus of elasticity in juvenile wood of Pinus radiata at two locations in Australia. Can J For Res 37:2164-2174

Blackburn D, Hamilton M, Harwood C, Innes T, Potts B, Williams D (2010) Stiffness and checking of Eucalyptus nitens sawn boards: genetic variation and potential for genetic improvement. Tree Gene Genomes 6:757-765

Borralho NMG, Cotterill PP, Kanowski PJ (1993) Breeding objectives for pulp production of Eucalyptus globulus under different industrial cost structures. Can J For Res 23:648-656

Brawner JT, Bush DJ, Macdonell PF, Warburton PM, Clegg PA (2010) Genetic parameters of red mahogany breeding populations grown in the tropics. Aust For 73:173-183

Brawner JT, Lee DJ, Hardner CM, Dieters MJ (2011) Relationships between early growth and Quambalaria shoot blight tolerance in Corymbia citriodora progeny trials established in Queensland, Australia. Tree Genet Genomes 7:759-772

Brawner JT, Meder R, Dieters M, Lee DJ (2012) Selection of Corymbia citriodora for pulp productivity. Southern For 74:121-131

Burdon RD (1977) Genetic correlation as a concept for studying genotype $\mathrm{x}$ environment interaction in forest tree breeding. Silvae Genet $26: 168-175$

Clarke B, McLeod I \& Vercoe T (2009). Trees for farm forestry: 22 promising species. A report for the RIRDC/Land \& Water Australia/ FWPRDC Joint Venture Agroforestry Program. 239 pages

Costa e Silva J, Borralho NMG, Araujo JA, Vaillancourt RE, Potts BM (2009) Genetic parameters for growth, wood density and pulp yield in Eucalyptus globulus. Tree Genet Genomes 5:291-305

Dieters MJ, White TL, Hodge GR (1995) Genetic parameter estimates for volume from full-sib tests of slash pine (Pinus elliottii). Can J For Res 25:1397-1408

Dombro DB (2010) Eucalyptus pellita: Amazonia Reforestation's red mahogany-an e-book for tropical tree investors. http://www. myreforestation.com. Accessed 25 Sep 2013

Downes GA, Worledge D, Schimleck L, French J, Beadle CL (2006) The effect of growth rate and irrigation on the basic density and kraft pulp yield of Eucalyptus globulus and E. nitens. New Zealand Forestry J 51:13-22

Dungey HS, Matheson AC, Kain D, Evans R (2006) Genetics of wood stiffness and its component traits in Pinus radiata. Can J For Res 36: $1165-1178$

Eldridge K, Davidson J, Harwood C, van Wyk G (1993) Eucalypt domestication and breeding. Clarendon, Oxford

Falconer DS (1981) Introduction to quantitative genetics. Longman, London and New York

Falconer DS, Mackay FC (1996) Introduction to quantitative genetics. Longman, Burnt Mill, England

Greaves BL, Borralho NMG, Raymond CA (1997) Breeding objective for plantation eucalypts grown for production of kraft pulp. For Sci 43:465-472

Griffin AR, Cotterill PP (1988) Genetic-variation in growth of outcrossed, selfed and open-pollinated progenies of Eucalyptus regnans and some implications for breeding strategy. Silvae Genet 37:124-131

Hamilton MG, Raymond CA, Harwood CE, Potts BM (2009) Genetic variation in Eucalyptus nitens pulpwood and wood shrinkage traits. Tree Genet Genomes 5:307-316

Hamilton MG, Potts BM, Greaves BL, Dutkowski GW (2010) Genetic correlations between pulpwood and solid-wood selection and objective traits in Eucalyptus globulus. Ann For Sci 67:511

Hardiyanto EB (2003) Growth and Genetic Improvement of Eucalyptus pellita in South Sumatra, Indonesia. In: Turnbull JW (ed) Eucalypts in Asia. Proceedings of an international conference held in Zhanjiang, Guangdong, People's Republic of China. p. 82-88

Harwood CE (1998) Eucalyptus pellita: an annotated bibliography. CSIRO, Canberra

Harwood CE, Alloysius D, Pomroy P, Robson KW, Haines MW (1997) Early growth and survival of Eucalyptus pellita provenances in a range of tropical environments, compared with E-grandis, Europhylla and Acacia mangium. New For 14:203-219

Hillis WE \& Brown AG (1978) Eucalypts for wood production. CSIRO, Canberra

Hodge GR, Dvorak WS (2001) Genetic parameters and provenenance variation of Pinus caribaea var. hondurensis in 48 international trials. Can J For Res 31:496-511

Hodge GR, Dvorak WS, Uruena H, Rosales L (2002) Growth, provenance effects and genetic variation of Bombacopsis quinata in field tests in Venezuela and Colombia. For Ecol Manage 158:273-289 
ITTO (2006) Guide on utilization of eucalyptus and acacia plantations in China for solid wood products. In: Technical report: improved and diversified use of tropical plantation timber in China to supplement diminishing supplies from natural forests. Chinese Academy of Forestry Beijing. http:/www.itto.int/files/user/pdf/publications/ PD\%2069\%2001/pd69-01-1\%20rev2\%28I\%29\%20e.pdf. Accessed Mar 2014

Kha LD, Thinh HH \& Cuong NV (2003) Improvement of eucalypts for reforestation in Vietnam. In: Turnbull JW (ed) Eucalypts in Asia. Proceedings of an international conference held in Zhanjiang, Guangdong, People's Republic of China. p 71-81

Lee JD, Brawner TJ, Smith ET, Hogg WB, Meder R \& Osborne OD (2011) Productivity of plantation forest tree species in north-eastern Australia: A report from the Forest Adaptation and Sequestration Alliance. In. A report prepared for the Australian Government Department of Agriculture, Fisheries and Forestry Sunshine Coast. 50 pages

Leksono B, Kurinobu S, Ide Y (2006) Optimum age for selection based on a time trend of genetic parameters related to diameter growth in seedling seed orchards of Eucalyptus pellita in Indonesia. J For Res 11:359-364

Leksono B, Kurinobu S, Ide Y (2008) Realized genetic gains observed in second generation seedling seed orchards of Eucalyptus pellita in Indonesia. J For Res 13:110-116

Luo J, Arnold RJ, Aken K (2006) Genetic variation in growth and typhoon resistance in Eucalyptus pellita in south-western China. Aust For 69:38-47

MacDonald AC, Borralho NMG, Potts BM (1997) Genetic variation for growth and wood density in Eucalyptus globulus ssp. globulus in Tasmania (Australia). Silvae Genet 46:236-241

Matheson AC, Raymond CA (1984) Effects of thinning in progeny tests on estimates of genetic-parameters in Pinus-radiata. Silvae Genet $33: 125-128$

Meder R, Marston D, Ebdon N, Evans R (2011) Spatially-resolved radial scanning of tree increment cores for near infrared prediction of microfibril angle and chemical composition. J Near Infrared Spec 18:499-505

Miranda I, Pereira H (2002) Variation of pulpwood quality with provenances and site in Eucalyptus globulus. Ann For Sci 59:283-291

Miranda I, Almeida MH, Pereira H (2001) Influence of provenance, subspecies, and site on wood density in Eucalyptus globulus Labill. Wood Fiber Sci 33:9-15
Patterson HD, Thompson R (1971) Recovery of inter-block information when block sizes are unequal. Biometrika 58:545-554

Pliura A, Zhang SY, MacKay J, Bousquet J (2007) Genotypic variation in wood density and growth traits of poplar hybrids at four clonal trials. For Ecol Manage 238:92-106

Poke FS, Raymond CA (2006) Predicting extractives, lignin, and cellulose contents using near infrared spectroscopy on solid wood in Eucalyptus globulus. J Wood Chem Technol 26:187-199

Raymond CA (2002) Genetics of Eucalyptus wood properties. Ann For Sci 59:525-531

Raymond CA, Schimleck LR (2002) Development of near infrared reflectance analysis calibrations for estimating genetic parameters for cellulose content in Eucalyptus globulus. Can J For Res 32:170 176

Sanhueza RP, White TL, Huber DA, Griffin AR (2002) Genetic parameters estimates, selection indices and predicted genetic gains from selection of Eucalyptus globulus in Chile. For Genet 9:19-29

Savitzky A, Golay M (1964) Smoothing and differentiation of data by simplified least squares procedures. Anal Chem 36:1627-1639

Schimleck LR, Kube PD, Raymond CA (2004) Genetic improvement of kraft pulp yield in Eucalyptus nitens using cellulose content determined by near infrared spectroscopy. Can J For Res 34:2363-2370

Schimleck LR, Kube PD, Raymond CA, Michell AJ, French J (2006) Extending near infrared reflectance (NIR) pulp yield calibrations to new sites and species. J Wood Chem Technol 26:299-311

Tran HQ, Nguyen DK, von Arnold S, Jansson G, Ha HT, Clapham D (2010) Relationship of wood composition to growth traits of selected open-pollinated families of Eucalyptus urophylla from a progeny trial in Vietnam. New For 39:301-312

Wei X, Borralho NMG (1997) Genetic control of wood basic density and bark thickness and their relationships with growth traits of Eucalyptus urophylla in south east China. Silvae Genet 46:245-250

White TL, Hodge GR (1989) Predicting breeding values with applications in forest tree improvement. Kluwer Academic Publishers, London

White TL, Adams WT, Neale DB (2007) Forest Genetics. CAB International, Oxford

Williams ER, Matheson AC, Harwood CE (2002) Experimental design and analysis for tree improvement, 2nd edition. CSIRO, Collingwood

Zobel BJ, van Buijtenen JP (1989) Wood variation: its causes and control. Springer, Heidelberg, Germany 